\title{
Etnografia é, Etnografia não é
}

\author{
John L. Jackson Jr. \\ University of Pennsylvania, Filadélfia, EUA \\ E-mail: jjackson@sas.upenn.edu
}

\section{Tradução: Felipe Neis Araujo ${ }^{1}$}

Universidade Federal de Santa Catarina, Florianópolis, Brasil E-mail:neis.araujo@gmail.com 


\section{Resumo}

Usando uma noção de "digital" como uma de suas metáforas principais, uma versão do termo dependente da discussão de Kara Keeling sobre o "humanismo digital", esse artigo argumenta que há algo sobre as não linearidades que definem a diferença da digitalidade que pode nos ajudar a pensar sobre recalibrações no próprio projeto etnográfico. De uma discussão da representação cinematográfica de Marlon Riggs sobre sua própria morte (como um modo de falar sobre o não digital) a uma máquina que usa a tecnologia digital para jogar com temporalidade na transmissão televisiva, este artigo quer indagar o que as mudanças nas relações sociais (e realidades existenciais) predicadas na onipresença da mídia digital podem significar para pesquisa e escrita etnográficas de hoje. Com os Africanos Hebraicos Israelitas de Jerusalém como sujeitos etnográficos centrais, argumento que tomar a digitalidade a sério significa redefinir algo do que a etnografia é e não é num momento pós-Writing Culture.

Palavras-chave: Digitalidade. Diáspora. Negritude. Etnografia. Antropologia da Mídia.

\section{Abstract}

Using a notion of "the digital" as one of its master metaphors, a version of the term reliant on Kara Keeling's discussion of "digital humanism," this piece argues that there is something about the nonlinearities defining digitality's difference that might help us to think about recalibrations in the ethnographic project itself. From a discussion of Marlon Riggs's filmic depiction of his own death (as one way to talk about the nondigital) to a machine that uses digital technology to play with temporality in broadcast television, this article wants to ask what the changing social relations (and existential realities) predicated on the ubiquity of digital media might mean for ethnographic research and writing today. With the African Hebrew Israelites of Jerusalem as central ethnographic subjects, I argue that taking digitality seriously means redefining some of what ethnography is and ain't in a postWriting Culture moment. [digitality, diaspora, blackness, ethnography, media anthropology]

Keywords: Digitality. Diaspora. Blackness. Ethnography. Media Anthropology. 


\section{A Morte de Marlon Riggs}

耳u me lembro de ter assistido à morte de Marlon Riggs. Era 1994 e eu estava na pós-graduação, escrutinando, quase literalmente, sua imagem fantasmagórica numa sala de aula do quarto andar da Schermerhorn Extension, prédio que abriga o Departamento de Antropologia da Universidade de Columbia.

O moribundo e a morte não eram menos reais por conta de sua conclusão não visualizada ou pelo fato de eu tê-los visto por meio de uma máquina de vídeo que consistia no empilhamento totêmico de uma televisão posicionada acima de diversos aparelhos de videocassete, cabos de áudio, vídeo e cabos de energia pendendo descuidadamente dos lados.

Em forma de reflexividade fílmica mais rigorosa do que qualquer coisa que eu houvesse visto antes, Riggs, um documentarista controverso que já havia sido acusado de ser um pervertido que não merecia o financiamento concedido pelo Senado dos Estados Unidos para seu filme anterior, Tongues Untied (1989), uma meditação sobre a masculinidade de gays negros, decidiu usar seu último documentário, Black Is, Black Ain't ([1994], um filme sobre a abertura, apesar da não vacuidade de negritude como um significante) para registrar em crônica seu próprio fim, sua própria morte, seu corpo definhando a cada cena que se passava por causa da AIDS.

Black Is, Black Ain't, antropológico em seu holismo voluptuoso, sinaliza e registra em crônica todas as marcas sobredeterminadas (inclusive clichês) da suposta negritude: cabelos texturizados, traços faciais, tons de pele, striding gaits, gêneros musicais, histórias políticas, lendas locais, ansiedades existenciais, cargos estereotipados, 
aculturações sexistas - tudo, incluindo, literalmente, fotos de pias de cozinha, o preparo do gumbo, um ensopado do Sul da Louisiana, como sua metáfora central do ecletismo e da heterogeneidade Afroamericanos.

Ao final do filme, entretanto, há duas imagens das mais assombrosas: (1) tomadas desfocadas de um Riggs esquelético, nu e sozinho, fazendo cooper da melhor forma que seu corpo adoentado conseguia num bosque iluminado pelo sol; e (2) um Riggs acamado e hospitalizado, explicando com esforço como ele queria que seu filme terminasse, um fim que ele próprio certamente não veria. A narrativa de Riggs, nas últimas sequências do filme, é intercalada [punctuated] por cálculos precisos da queda de linfócitos e perda de peso, uma bolsa térmica em cima de seu estômago inchado e com problemas de digestão, acena para o lento fim e para a materialidade mutante da vida humana, aquilo que Ralph Waldo Emerson certa vez chamou de "a irresistível democracia" da decomposição física, toda terra volta para a terra - das cinzas às cinzas, do pó ao pó.

Eu sempre considerei Black Is, Black Ain't uma autoetnografia ilícita e inquietante de uma excentricidade audaciosa [courageous strangeness], especialmente por sua habilidade hipnótica de fisgar seus espectadores tornando-os voyeurs volitivos e não contristados. Eu passei a aceitar a minha função como voyeur, fixando os olhos na morte e recusando desviá-los, sendo incapaz de fazê-lo. É o tipo de filme hiper-reflexivo que espeta e estimula a alma, que oferece (ao menos para mim) um início de viagem a um campo midiatizado [one mass-mediated field site] do qual uma parte de meu subconsciente antropológico jamais retornou completamente.

Muitos anos mais tarde, eu tive a primeira oportunidade de assistir à representação fílmica de Barbara Myerhoff de sua própria morte, a oferenda In Her Own Time, de 1985, uma meditação sobre sua relação com o judaísmo, lançado cerca de um ano antes da publicação de Writing Culture (Clifford; Marcus, 1986), a obra que ajudou a destacar a reflexividade como uma das intervenções centrais da antropologia, concomitantemente fortalecendo a parte do campo mais vulnerável à ridicularização transdisciplinar: seu presumido solipsismo, uma 
reflexividade disciplinar supostamente levada a extremos doentios. O filme de Myerhoff não é nem de perto tão citado ou evocado, e por razões que podem ter a ver com o modo com o qual conduz seu investimento em reflexividade - uma reflexividade que é tanto arte quanto ciência.

Devorar Writing Culture me deixou ansioso para conduzir meu próprio trabalho de campo. Menos, confesso, pelo fascínio intrínseco, pela interação brusca e tropeçante "do campo" (com seus intercâmbios por vezes alarmantes e difíceis de lidar, o tipo de situações para as quais eu invocava o Anthroman, meu alter ego etnográfico), e mais por conta da licença que o livro proporcionou para pensar de forma destemida sobre a própria escrita, martelando o último prego do caixão de uma pretensão central da antropologia, a de que as monografias etnográficas não seriam problemáticas, já que serviriam como janelas transparentes para alguma floresta cultural lá fora, além do texto. Isso implicou na surrealização da representação etnográfica, tornando-a uma caixapreta (diferente dos anseios mais positivistas que eu via na sociologia qualitativa), assim como deu início a uma delineação meticulosa das técnicas de escrita utilizadas para fabricar autoridade científica em primeiro plano. Parecia um paradoxo poderoso: explicação e mistificação ao mesmo tempo. Apesar das críticas que se seguiram pela falta de atenção à raça e ao gênero como enquadres analíticos (da parte de intelectuais como Faye Harrison [1997] e outros) parecerem legítimas, eu ainda estava determinado a me inscrever no projeto Writing Culture, a abraçar seus voos de fantasia representacional, reconhecendo sem temeridade a dimensão estética da escrita antropológica, uma ciência social (como qualquer outra ciência social) coproduzida por meio de floreios retóricos e inclusive de habilidades literárias.

Anna Grimshaw (2011) descreve o contraste entre um frequente menosprezo da estética e as aspirações de objetividade de uma verdadeira ciência social como uma das principais clivagens que desqualifica os filmes de seu lugar de direito na academia. A discussão talvez remeta alguns leitores à época das famosas críticas de Clifford Geertz a pesquisadores pelo movimento de "intuicionismo e alquimia" ou mero "esteticismo sociológico". Tais preocupações e críticas ajudariam a 
explicar, argumenta Grimshaw, porque apesar de os antropólogos terem se valido de tecnologias de filmagem em trabalhos etnográficos desde o início do século XX, a Associação Americana de Antropologia ainda precisaria emitir uma nota quase 100 anos mais tarde implorando às instituições acadêmicas a levarem a produção audiovisual em conta quando avaliassem os acadêmicos para progressão funcional. Essa é uma das principais razões para que não se dê aos filmes etnográficos a mesma importância atribuída a livros ou artigos na maior parte dos contextos acadêmicos. O problema dos filmes, diria ela, é que eles sempre se inclinam para a estética, para o emocional, o artístico, o afetivo e, talvez, como Csordas (2002) colocaria, para o "pré-objetivo". Essa estetização da pesquisa antropológica sempre foi, para muitos antropólogos, um convite sedutor, e Writing Culture representou um ponto crucial de engajamento com esses desejos acadêmicos.

John Durham Peters (1999) sugere que as novas tecnologias de mídia, desde o telégrafo até o telefone, do rádio à televisão, da fotografia ao filme, foram sempre baseadas no esforço de rechaçar a morte, de transcender nossa mortalidade (em verdade, diria ele, de transcender nossa humanidade) em busca de formas de finalmente nos comunicarmos como (e com) os anjos ou deuses - sem mediação, sem a materialidade cafona dos significantes, rompendo caminhos por meio das interioridades emparedadas que ostensivamente nos separam e alienam uns dos outros. Todos os meios de comunicação são, de certo modo, comunicação com os mortos, o que é uma interpretação daquilo que Roland Barthes (1981) afirma sobre a "indexicalidade" das fotografias: que elas são, em verdade, fotografias de espíritos, vislumbres da iminência de nossa própria morte e uma forma de enxergar através desse grande véu. É uma tentativa de assistirmos a nossa própria morte.

Riggs imagina que seu filme irá proporcionar certa transcendência da morte, assim como recorre aos afagos amorosos de seus familiares como aquilo que o permitirá, afinal, morrer em paz. Cada vez mais "o fílmico" serve como instanciação central da cultura, como fato metacultural da existência contemporânea, como meu colega da Universidade da Pensilvânia, Greg Urban (2001), enquadraria. Essa 
é uma noção do fílmico que está cada vez mais ligada às lógicas não lineares, temporalmente texturizadas e até mesmo potencialmente desafiadoras da morte das novas tecnologias digitais - com o "digital" ostentando poderes quase fetichistas em algumas evocações acadêmicas contemporâneas. O que este "digital" implica para a escrita [writing] da cultura hoje? Até que ponto assistir o filme de Riggs (em VHS, confessamente, não em DVD) é um componente necessário daquilo que pode significar estudar "cultura" no século XXI? E como se escreve sobre essas observações antes mesmo de começar a jogar com as possibilidades de filmá-las? Que tipo de escrita a potencial digitalização da cultura demanda e possibilita?

\section{A Máquina do Tempo}

No início deste novo milênio, um grupo de homens barbudos do que parecia ser uma comunidade espiritual excêntrica baseada no sul de Israel abordou um empresário bem-sucedido afro-americano com uma proposta de negócios. O empresário estabelecido na Filadélfia conhecia muito pouco da vida destes homens, ou do grupo transnacional que eles representavam, mas ficou intrigado com a ambiciosidade de suas falas persuasivas. Os termos relacionais da proposta mudariam radicalmente com o tempo (de um pedido de capital de risco sem a participação do empresário a configurações mais colaborativas de parceria transatlântica, até um cenário final onde o homem de negócios e sua família desempenharam, decididamente, um papel de liderança no empreendimento todo), mas a ideia, o empreendimento pretendido, era claro e fixo.

Os homens de Israel queriam ajuda para adquirir direitos de vender e arrendar uma invenção que reduzia imperceptível e automaticamente os programas de televisão, permitindo às emissoras e às operadoras de TV a cabo adicionarem ainda mais tempo de propagandas a suas transmissões diárias. Esse aparato relativamente novo não apagava cenas inteiras ou longas sequências contíguas de cenas das atrações, técnica tradicional (e bastante conspícua) da qual as emissoras se valem para "reformatar" filmes concebidos para salas de cinema de forma que se encaixem na ordem da programação. A tecnologia também era 
muito mais sofisticada do que as primeiras invenções que tentaram espremer filmes em espaços de tempo pontuados por propagandas acelerando determinadas sessões, outra maneira simples (embora às vezes distraidamente notável) de diminuir a duração de uma atração.

Os homens estavam empenhados em adquirir a propriedade de um dispositivo mecânico ultramoderno, baseado em tecnologia digital avançada, e introduziram seu potencial parceiro de negócios às especificidades do aparelho, fornecendo detalhes sobre a máquina que cobiçavam, que trabalha nas unidades de frame, pré-escaneando e digitalizando o material, eliminando de forma intermitente os enquadres redundantes que funcionam como duplicatas aos olhos humanos, o que torna as exclusões quase imperceptíveis. Há enquadres redundantes o bastante na retransmissão de um longa-metragem de duração média, ou de uma partida de futebol, para abrir espaço a vários anúncios de 30 segundos - e sem grandes impactos no conteúdo narrativo ou no fluxo temporal. Essa máquina oferece uma maneira de lucrar com o previsível interesse da mídia televisiva em meios mais sutis de espremer mais receita publicitária de cada hora-padrão de anúncios televisivos, vendendo uma forma de burlar o próprio sistema da mídia (hiperexplorando sua dependência de anunciantes). De alguma forma, a vida social desses homens na região israelense de Negev ajuda a explicar algumas das razões pelas quais eles possivelmente se interessaram por esse ramo da tecnologia - e porque foram motivados a capitalizar em cima da lógica cultural de uma indústria de mídia que interage produtivamente com sua própria empresa.

Eu evoco essa breve capitulação de um conto sobre um arranjo de negócios em torno de um equipamento de mídia que precisamente manipula a temporalidade (sem aparentemente fazê-lo) como um meio de discutir como as novas tecnologias reenquadram e reformatam formulações tradicionais (pré-digitais?) de comunidades diaspóricas - e das representações etnográficas. De forma semelhante à diferença de escala entre, digamos, uma cena e os quadros que a constituem, uma diferença mais facilmente (até automaticamente) explorável por tecnologias como a engenhoca supracitada, projetada para aparar programas intrincadamente sem causar impactos notáveis no enredo 
ou frustrar os aspectos visuais e auditivos de nosso sistema sensorial, eu pretendo que este breve artigo evoque algumas das formas nas quais podemos construir uma conversa produtiva sobre refigurações de tempo e espaço etnográficos por meio da digitalidade e de seus diversos desdobramentos (Ginsburg, 2008). O que eu quero destacar aqui, na verdade, é uma simples (apesar de um tanto controversa) afirmação de que "o diaspórico" e "o etográfico" tornaram-se, em certo sentido, "digitais", uma vez que modalidades avançadas de mediatização de massa criam e recriam formas de sociabilidade e mesmo de intimidade que demandam e gratificam a atenção da crítica. Esta digitalização é desproporcionalmente distribuída, é claro. Mesmo que se argumente que as "diásporas digitais" não são simples extensões de, digamos, "exclusão digital" racializada, o digital ainda pode ter inflexões etnocêntricas quando se presume acriticamente que ele seja o tipo de rubrica universal que não é (Everett, 2009; Ginsburg, 2008).

Os homens que abordaram aquele que seria seu financiador em 2002 tem um conto diaspórico particularmente interessante. Eles eram emissários de um grupo de expatriados afro-americanos que emigraram dos Estados Unidos para a Libéria em 1967 antes de se mudarem, finalmente, para Israel, em 1969, onde vivem desde então. Este grupo, os Israelitas Hebreus Africanos de Jerusalém (AHIJ), fornece um exemplo do que uma noção como "diáspora digital" ajuda a capturar. Tecnologias digitais e "new media" fornecem a cola que mantém sua comunidade espiritual desterritorializada unida, uma comunidade que se espalha por quatro continentes e continua a compelir com êxito mais pessoas para juntar-se a suas fileiras.

E não é mera casualidade que um grupo como este gravite ao redor de inovações tecnológicas baseadas em temporalidades reenquadradas. Sua própria viagem no tempo (incluindo o "êxodo" da América Babilônica, a estadia no "deserto" da Libéria e o eventual restabelecimento na "terra prometida", um estado moderno de Israel regeografizado como o "Nordeste da África") está baseada num sentido fortemente atualizado [refrashioned] de possibilidade temporal, numa contemporização da estória do Antigo Testamento dos Antigos Israelitas, considerados antepassados genealógicos pela comunidade dos AHIJ. Vou deixar a investigação da releitura sutil do Antigo Testamento pela comunidade 
para outra ocasião. Neste pequeno texto eu gostaria apenas de justapor vários quadros e cenas de mediatização de massa que constituem o presente regime diaspórico da comunidade com uma afirmação sobre como a própria artimanha etnográfica está implicada em tal discussão. Os membros da comunidade AHIJ viajam transnacionalmente, e são as implementações das tecnologias de mídia mais atuais (programas de rádio online, sítios virtuais mantidos pela comunidade, uploads para o YouTube, circulação de filmes digitais produzidos pela comunidade) que fornecem alguns dos mais poderosos mecanismos para o cultivo de formas de comunhão e de investimentos mútuos que permitiram que esta comunidade de emigrantes sobrevivesse por mais de 40 anos.

Este artigo traz uma série de pequenas seções que eu gostaria que os leitores interpretassem como enquadres constitutivos para pensar por meio das várias formas de midiatização de massa que sobredeterminam a prática etnográfica no momento atual. Essa é uma evocação de enquadre tanto no sentido de (1) um gesto em direção à contextualização (um enquadre conceitual de problemas relevantes) quanto (2) de uma impressão singular capturada no tempo (como na apresentação de uma pintura enquadrada ou da relativa irredutibilidade de um filme ou de uma captura de imagem de um vídeo). Mas esta captura não significa invocar uma espécie de taxidermia, uma simulação imutável e sem vida de realidades vividas inertes e congeladas. Como Bhabha, Clifford e outros nos lembraram, temporalidades diaspóricas e minoritárias são (para usar um termo taussigiano) "nervosas" com movimento e agitação, princípios organizativos recursivos e fractais que oferecem lógicas não lineares de possibilidade diacrônicas - não linearidade, shsom, sendo uma versão da diferença fundamental do digital. Kara Keeling (2005) argumenta que tal não linearidade (suposições sobre acesso diferenciado a lógicas temporais não cronológicas) há muito determina a exclusão dos povos Africanos e Afro-americanos da subjetividade ocidental moderna, sendo os últimos mapeados numa suposta trajetória linear chamada "progresso". O argumento de Keeling é que a exclusão Afro está cada vez mais se tornando a regra global, criando angústias e nervosismo existencial para os recentemente não linearizados por meio da ascensão da era digital [digitality]. Aquilo que pode ser chamado de "temporalidades etnográficas" carrega um nervosismo semelhante, 
e as afirmações de Keeling têm implicações tanto para as discussões etnográficas quanto para as diaspóricas. Meu acionamento do enquadre pretende canalizar o argumento de Keeling e também proporcionar uma metáfora produtiva para marcar o que Brian Axel chama (em sua conceituação de diáspora) "temporalidades díspares (anterioridades, presentes, futuridades), deslocamentos e assuntos". Eu ofereço esses enquadres, então, como blocos de construção para uma montagem analítica que fornece um rápido olhar para algumas concatenações e imbricações que constituem as possibilidades diaspórica e etnográfica hoje. As primeiras duas seções deste artigo representam dois destes enquadres. Há mais três que eu gostaria que os leitores vissem.

\section{O Centro Audiovisual da Verdade}

Os Israelitas Hebreus Africanos de Jerusalém estão sediados em Dimona, mas os "santos", como os adeptos são chamados, podem ser encontrados em Israel e ao redor do mundo todo. Os membros da comunidade passaram as décadas de 1970 e 1980 como "residentes temporários" em Israel, o que significa que receberam pouca assistência governamental e foram impedidos de serem empregados legalmente. Eles trabalharam, de qualquer forma, geralmente de maneira informal em construções, construindo em segredo casas para beduínos nômades africanos forçados à vida sedentária pelo recenseamento e pela coleta de impostos do estado de israelense. Às vezes, eram presos e deportados para os Estados Unidos quando estavam empregados em tais ofícios, o que exigia tramar esquemas elaborados (e às vezes ilegais) para ter êxito no retorno à região de Negev.

Os AHIJ se estendem para além da Israel contemporânea, consistindo em comunidades-satélite ao redor do mundo todo. Se 2,500 a 3,500 santos vivem atualmente em Israel (alguns dizem que são cerca de 5,000), muitos mais residem no estrangeiro, nas Índias Ocidentais, na África, na Europa e nos Estados Unidos. O grupo tem "extensões" oficiais em todos os Estados Unidos (Chicago, Atlanta e Washington D.C). São três das maiores comunidades e comunidades semioficiais (ou ascendentes) em outras partes do mundo, incluindo Gana, África do Sul e Benin. 
O Ministério de Informação dos AHIJ fica na extremidade de seu complexo em Dimona, um dos muitos edifícios ondulados de aço e cimento que circundam um pequeno lote de concreto no centro de sua kfar (vila). O Ministério de Informação é ligado ao Instituto Escola dos Profetas (a instituição de ensino ou "dedicação" superior autocredenciada da comunidade) e abrange o Centro Audiovisual da Verdade (ATVC, na sigla em inglês), seu braço de produção midiática. É ali que eu passaria boa parte de meu tempo etnográfico durante passagens por Israel, conversando com os santos que faziam as instalações de mídia funcionar e observando sua vasta coleção de vídeos.

Os AHIJ são incríveis autoarquivistas intencionais, o que significa que eles filmam muitos dos feriados anuais da comunidade, inclusive a Páscoa do Novo Mundo, um evento festivo de dois dias que comemora a saída do grupo original dos Estados Unidos em 1967. A ATVC grava eventos especiais com Ben Ammi, o Messias do grupo, em diversas localidades da kfar e do país, além de programas relevantes de canais estadunidenses e europeus televisionados via satélite. Consequentemente, o prédio de audiovisual contém milhares e milhares de horas de imagens nos formatos DVD e VHS, sendo a maior parte dos materiais gravada pelos próprios santos. Muitos dos membros jovens da comunidade são cineastas (estudando em escolas próximas à comunidade e desenvolvendo suas habilidades em produções baseadas nela), e são responsáveis por muitas das filmagens organizadas fora do AVTC (em acordo com o Ministro da Informação, o Sar [Ministro], que supervisiona toda a operação). Quando Bobby Brown e Whitney Houston visitaram a comunidade em 2002, um evento que atraiu a atenção da mídia internacional, o episódio inteiro foi narrado pelos produtores do AVTC em vídeo digital com horas e horas de filmagens. Quando a construção de um novo complexo parecido com a kfar foi finalizada no Benin, uma elaboração grandiosa da versão de Dimona totalmente projetada pelos santos da comunidade, o AVTC certificou-se de filmar todo o local, destacando seus diversos aparatos institucionais ( salões de banquete, instalações industriais, áreas de cultivo, salas de aula etc.), capturando em vídeos seu vasto tamanho (que supera em muito a kfar em Dimona) e descrevendo seu potencial impacto no Benin em termos econômicos e culturais. 
Para uma comunidade sensível em relação a sua imagem pública e propensa a ser julgado como um culto, o Ministério da Informação e o AVTC (em conjunto com o Gabinete de Relações Públicas da comunidade) são o marco zero para contra-ataques discursivos às acusações de patologia e criminalidade. Alguns meses após minha primeira visita à comunidade o Jerusalem Post publicou um artigo, "Suspeitas em Dimona", relatando que o Instituto Nacional de Seguros havia infiltrado um agente disfarçado na comunidade dos AHIJ tentando provar rumores de que os santos estariam defraudando requerimentos de benefícios de seguros avaliados em milhões de dólares. Dizia-se que o FBI e o Departamento de Estado dos E.U.A. estariam colaborando com o NII nas investigações.

No início do século XXI, os AHIJ finalmente receberam o estatuto de residência permanente (uma tentativa de "normalizar" suas ligações com Israel e de formalizar explicitamente seu caminho para a cidadania plena), o que significa que eles se tornaram elegíveis para requerer benefícios do NII. De acordo com o artigo, "autoridades israelenses" manifestaram preocupações acerca do fato "de que não podiam calcular a população exata da comunidade, uma vez que as estimativas variam entre 2,000 a 4,000 pessoas" (novamente, algumas pessoas afirmavam haver cerca de 5,000 pessoas em 2012). Mesmo agora que os adultos que receberam o estatuto de residência permanente têm numeração identitária, é impossível determinar o tamanho da comunidade. As crianças nascem dentro da comunidade, sem a utilização de hospitais ou medicamentos convencionais - e o que mais preocupa o NII: sem uma listagem oficial. As autoridades não têm um meio preciso para registar recém-nascidos e falecidos. A relativa impenetrabilidade da comunidade aos olhos curiosos do Estado é constantemente referida como uma de suas características mais ameaçadoras nestas notícias e relatos investigativos recorrentes. Os apelos para tornar os AHIJ cidadãos plenos de Israel são, na verdade, ao menos em parte, baseados na ideia de que tal movimento criaria, finalmente, uma transparência social mais favorável à inspeção burocrática.

Houve inclusive alegações contínuas de que os líderes da comunidade estariam encorajando explicitamente mulheres AHIJ a registrar as crianças com funcionários do NII sob nomes diferentes 
- para que a comunidade pudesse receber vários benefícios. O artigo mencionado acima percorre muitas destas alegações, mas não oferece nenhuma prova concreta, apenas especulações baseadas no relativo sigilo do grupo e em sua opacidade. Mesmo assim a comunidade está em guarda contra esta propaganda negativa, e o Ministério da Informação (por meio do AVTC) fica encarregado de ajudar a disseminar contranarrativas do sucesso dos AHIJ e de seus avanços positivos, razão pela qual alguns detratores julgam a produção midiática da comunidade como pouco mais do que propaganda. Estas produções são geralmente destinadas a dois grupos de telespectadores: (1) aos santos no reino (na kfar em Dimona e ao redor do mundo) assim como (2) aos leigos inclinados a julgar a comunidade como um culto maluco (por terem se realocado do Sul de Chicago para o Sul de Israel e por suas afirmações de que os Americanos são descendentes genealógicos dos antigos israelitas, servindo as afirmações como justificativa da realocação). A forma como suas produções de mídia negociam as diferenças entre estas duas audiências articula-se em torno de uma valorização refinada de elasticidades discursivas e temporais que se unem e se afastam.

\section{DVD de Aniversário}

Quando Nasi Asiel bem Israel, o Embaixador Internacional Extraordinário Plenipotenciário dos AHIJ, fez 65 anos, o Centro Audiovisual da Verdade da comunidade produziu um documentário de 40 minutos sobre sua vida ${ }^{2}$. Esse vídeo narra seu nascimento (como Warren Brown) no Sul de Chicago no início da década de 1940 e sua tenra infância no infame conjunto habitacional Ida B. Wells. Sua estória individual é contada no contexto de uma narrativa afro-americana mais ampla, destacando a Grande Migração dos Negros Sulistas em direção ao Norte urbanizado, o assassinato brutal de Emmit Till, a criação da Motown Records, o atentado a bomba contra a igreja da Sixteenth Street, a recusa de Rosa Parks a ceder seu assento no ônibus e a fundação do Partido dos Panteras Negras. Para a Defesa Pessoal, todos eles aspectos canonizados na maior parte das releituras das vidas dos afro-americanos no século XX. 
O documentário também cobre a graduação de Brown no Duynbar High School (como primeiro aluno da turma), o reconhecimento público de seu status como um dos melhores alunos de toda Chicago e sua posterior matrícula na DePaul University. Enquanto se graduava na faculdade, tornou-se membro da confraria Alpha Phi Alpha, uma organização afro-americana, conheceu sua futura esposa, Harriet, e começou a vender jukeboxes a empresários negros, fazendo parte do negócio bem sucedido de seu padrasto em Chicago. Por volta de seus 26 anos de idade, Warren e Harriet conseguiram comprar uma casa num bairro de classe média de Chicago, e as pessoas que o conheciam melhor achavam que a combinação de inteligência e liderança nele poderia eventualmente torná-lo uma boa aposta para um cargo público municipal, talvez até como o primeiro prefeito negro de Chicago. Ele era bem-sucedido em relação à maior parte dos padrões da comunidade, mas, segundo sua esposa, "ainda não estava satisfeito".

Warren finalmente conheceu Nasi Shaleak Ben Yeduda (à época L. A. Bryant) em 1966 e tomou conhecimento da mensagem dos AHIJ. Por volta de 1971, ele estava em Israel com o resto daquele "grupo de vanguarda" de emigracionistas e fora ungido como um dos 12 Príncipes de Ben Ammi, Nasi Asiel (Príncipe das Bênçãos). Asiel foi encarregado de trazer mais pessoas para o reino, e provou ser um embaixador incrivelmente eficiente. O documentário, uma homenagem a um ancião do grupo, é um "obrigado" visual por seu trabalho vitalício em nome da comunidade. Mas é também uma instanciação interessante da relação complicada dos AHIJ com a cultura afro-americana.

Uma das primeiras coisas impactantes deste curta é sua tentativa de integrar a comunidade dos AHIJ numa narrativa mais ampla de autenticidade cultural afro-americana. Para um grupo que muitas vezes é desclassificado categoricamente de um pertencimento racial-social por conta de sua distância das noções convencionais (e estereotipadas) da espiritualidade afro-americana (ligadas a afirmações normativas sobre conexões mais compreensíveis de afro-americanos com o Cristianismo e a Nação do Islã), este é um movimento bem calculado. Sua identificação literal (em oposição à identificação meramente metafórica) com os Antigos Israelitas os marca como radicalmente diferentes, até mesmo 
estranhos. Além do mais, seu discurso sobre as especificidades culturais afro-americanas geralmente os define como totalmente alheios àquela formação cultural normativa.

Segundo os AHIJ, a cultura afro-americana é patológica por ter sido corrompida pela cultura disfuncional dos Estados Unidos. Seu projeto é um exemplo clássico daquilo que Anthony Wallace (1956) descreveu como um "movimento de revitalização", que busca desafiar todo e qualquer aspecto de suas amarras culturais pré-determinadas - para os AHIJ, isto significa distanciar-se de práticas culturais afroamericanas: roupas, dieta, música, celebrações e educação. Todos os aspectos da particularidade cultural afro-americana são suspeitos e precisam de reabilitação, o faz com que a manobra do documentário para ligar a narrativa de Warren Brown a momentos canônicos das culturas popular e política afro-americanas no século XX - Rosa Parks, Emmit Till, Motown - seja tão fascinante. Esse gesto parece uma tentativa de remeter a comunidade a uma estória clássica da vida e da cultura afro-americanas, uma estória da qual buscam geralmente se separar. Com efeito, este vídeo da transformação de Warren Brown pode ser descrito como uma sutura temporal que não deixa rastros análoga às eliminações discretas daquele aparelho televisivo de cortar enquadres mencionado acima. De fato, o vídeo de aniversário pode ser lido como qualquer outro documentário do PBS sobre a história afro-americana em meados do século XX, de forma que é intencional, consciente e bastante eficaz.

Mais interessante ainda do que uma lógica narrativa que de outra forma seria bastante corriqueira (não fosse a recusa férrea da comunidade em relação a práticas culturais afro-americanas tradicionais) é o uso de imagens e sons para reforçar a estória do documentário. O filme começa com imagens canônicas (fotos e vídeos) de documentários famosos sobre a vida afro-americana, alguns dos quais os próprios documentários do PBS que simula. As cenas reimplantadas a partir das antigas atrações do PBS são notáveis por conta de seu próprio estatuto canônico: um vídeo frequentemente repetido da foto de Emmit Till posicionada acima de seu caixão aberto, imagens clássicas de pronunciamentos públicos a favor da segregação, de bebedouros 
exclusivos para brancos [Whites Only], imagens de manifestantes negros pacíficos, meras crianças, recebidos por cães e cassetetes de polícia. A maior parte dos telespectadores afro-americanos já assistiu a maioria destas imagens antes, e elas ainda se encontram claramente sob proteção autoral, mas são simplesmente recicladas de DVDs e fitas VHS de documentários como Eyes on the Prize e integradas a esse vídeo comemorativo sem citações explicitas. Nos créditos finais não estão listados nenhum dos filmes originais incluídos na reprodução. Os oferecimentos chegam sem as permissões ou citações convencionais.

A utilização de música no vídeo é semelhante. A narrativa se desenrola sobre composições de jazz conhecidas (incluindo "Kind of Blue", de Miles Davis) e hits da Motown, o que reforça as imagens de vídeo (e as referências narrativas) do início da gravadora e de seus artistas. Novamente, nenhuma das canções é listada nos créditos. Ao invés disto, elas são sampleadas sem permissão ou indenização - de modo parecido com os reimplantes de produções musicais ocorridos nos princípios do hip-hop. Essas violações de direitos autorais sugerem certa indiferença calculada aos princípios organizacionais e às lógicas culturais das relações capitalistas regidas por contrato. O próprio DVD parece fundamentar ainda uma espécie de forma de circulação anticapitalista de meios de comunicação. Assim como outros vídeos feitos pelos escritórios de produção midiática dos AHIJ, alguns dos quais carregam números de ISBN e etiquetas de preço colados nos cantos das caixinhas de plástico transparente, uma parte substancial do trabalho em vídeo da comunidade parece mobilizar as armadilhas e os equipamentos da mercantilização como uma espécie de artifício para o presenteamento - tanto dentro da comunidade quanto entre os nãomembros. Em certo sentido, a forma de mercadoria (e seus mandatos contextuais) parecem quase simular um tipo de capa protetora para uma forma de intercâmbio, uma modalidade que coloca potencialmente a construção da comunidade numa tensão produtiva com a mera comercialização. Essa dinâmica não é nada nova, especialmente agora que cada vez mais grupos investem em formas de automercantilização baseadas na capitalização das próprias diferenças étnicas e raciais (Comaroff; Comaroff, 2009). Assim como o conteúdo do DVD mobiliza produtos de áudio e vídeo para produzir um texto que não se dobra 
às expectativas dos padrões legais estabelecidos para este tipo de intertextualidade, sua forma pretensamente comoditizada parece jogar com a arquitetura das transações comercializadas sem tornar tais mandatos absolutamente obrigatórios. Dádivas desse tipo demandam, claro, outras obrigações, mas elas provocam curtos-circuitos em algumas das coisas que supostamente constituem a distinção das commodities.

Efetivamente, os livros de Ben Ammi, os textos sagrados dos AHIJ, parecem não ser intercambiados da mesma forma extracomercial, ao menos não na mesma proporção. Ele publicou ao menos uma dezena de livros, e eles são quase que exclusivamente comprados pelos santos, e não dados de presente. Mesmo um antropólogo interessado a quem se oferecem cópias gratuitas de DVDs ou CDs de diversos eventos e produções dos AHIJ tem de pagar por suas cópias das dádivas sagradas de Ammi, que circulam quase exclusivamente como mercadorias a venda - de forma oposta aos presentes que circulam sem pagamento. Algo da interessante ironia que consiste em livros sagrados serem vendidos e representações midiáticas seculares serem dadas como presentes parece demonstrar uma versão do paradoxo produtivo que anima o nexo no qual o espiritual e o econômico se encontram numa época de "capitalismo milenarista".

O esforço dos AHIJ para aproveitar as necessidades capitalistas dos meios de comunicação (por meio de uma máquina lhes permite encaixar mais anúncios na programação diária) revela uma espécie de tensão entre o sagrado ( seu projeto de redenção espiritual para toda a humanidade) e o aparentemente profano o sistema midiático global) que transforma em virtude o vício de outrora enquanto tenta negociar um momento ainda maduro, parece, para a colheita celestial.

Também se deve destacar, mesmo que apenas de passagem, que a meta final para os AHIJ é a vida eterna, a imortalidade física. Eles não acreditam que as pessoas têm de morrer. Então eles não querem documentar a inevitabilidade do fim da vida. Eles pretendem, ao invés disto, dramatizar o exato oposto, fornecendo um caminho bastante diferente para pensar como os humanos podem desafiar a morte. Não metaforicamente, via documentários filmados que nos permitem ver os mortos reanimados em vida, mas literalmente - permitindo 
que os corpos humanos vivam mais, muito mais. Eternamente. Eles usam o veganismo (aquilo que chamam de dieta "Edênica") como um elemento central de seu argumento sobre a capacidade do corpo de se regenerar (a nível celular) perpetuamente, o que é apenas mais uma razão do porque eles são bons para pensar em qualquer discussão sobre conceptualizações remodeladas da possibilidade temporal na idade contemporânea. ${ }^{3}$ E esta imortalidade pode ainda ser persuasivamente teorizada como outra forma de temporalidade não cronológica, ou mesmo como uma forma distinta para pensar sobre o digital - como algo que dura para sempre, uma postagem "sexista" num blog, um vídeo "racista" no YouTube, um tweet "inapropriado", todas coisas que continuam a circular de maneira semelhante a suas formas originais mesmo após seus autores os seus autores tê-los realizado.

\section{Insinceridade Etnográfica}

Deixe-me encerrar com uma questão sobre à medida que os etnógrafos estão cada vez mais acessíveis (e mesmo investigáveis), de forma sem precedentes, em função da tecnologia digital, o que inclui, mas não se limita, à construção proposital de selfs públicos encontrados em sítios eletrônicos como o Tweeter e o Facebook.

Há pouco tempo fui convidado a dar uma palestra na Costa Oeste baseada em minhas pesquisas com os AHIJ, e o evento foi divulgado com meses de antecedência no sítio virtual da faculdade. Algumas semanas antes da minha viagem da Filadélfia para a Califórnia, recebi uma ligação de um dos sujeitos de minha pesquisa desejando sorte com a palestra e pedindo mais informações sobre o que eu pretendia falar sobre eles. Eu não havia mencionado a palestra agendada, mas o santo teve pouca dificuldade para descobri-la. Até mesmo uma pesquisa sem inspiração de meu nome e da comunidade no Google a revelaria. E como todos nós sabemos, depois da realização dessas conversas de campus, elas são geralmente disponibilizadas on-line, tal como as pesquisas em andamento continuam acessíveis via rede por muito tempo. Dessa forma, mesmo que os membros da comunidade não ouçam falar da palestra agendada, podem assisti-la em vídeo muitos meses ou anos após ter sido realizada. 
Da forma que apresentamos cada vez mais nossas vidas profissionais na internet, torna-se cada vez mais fácil para sujeitos de pesquisa "estudar" e seguir os movimentos do etnógrafo no "backstage" (fora do contexto especificamente "etnográfico"). De fato, isso pode servir de exemplo de como "o etnográfico" está se expandindo de forma a incluir o que um dia foi descrito como além de seu alcance. Com relação àquela palestra no Oeste e sua potencial sobrevida on-line, temos um pequeno exemplo do acesso às regiões etnográficas ocultas que o momento proporciona. Apesar de nem toda a população ter acesso à internet, sem falar na igualdade de acesso, podemos imaginar um mundo onde tal acesso (não importa o quão torto e desigualmente distribuído) torna-se cada vez mais prevalecente, mesmo que nunca chegue perto da universalidade. E com isso surgem novas questões atiradas por meio do arco etnográfico. Por exemplo, este etnógrafo fala sobre seu projeto na academia da mesma forma que fala dele quando está no Sul de Israel, representando a si mesmo e seu trabalho para seus sujeitos?

O projeto etnográfico é baseado, tradicionalmente, na expectativa de que um etnógrafo acesse completamente os bastidores do "primitivo" sem necessariamente divulgar muito de si - ao menos não da mesma forma e na mesma medida. O etnógrafo está sempre gerindo, claramente, uma dança transcultural [cross-cultural] no campo, e ele pode realizar passos errados que o retratam de uma maneira que ele preferiria mascarar. Ainda assim ele sempre pode esconder o material dos bastidores em sua notória tenda. Mais ainda, ele eventualmente parte para "casa" com um tipo de finalidade que mantém os nativos distantes, mesmo os informantes mais interessados.

Com as novas tecnologias de mídia como a internet e o interesse conjunto da academia de reimplantar as potencialidades tecnológicas com fins pedagógicos, está cada vez mais fácil para os sujeitos em campo acessar e avaliar as apresentações do etnógrafo que antes ficavam nos bastidores (de volta ao "lar" na torre de marfim), mesmo que esses sujeitos não encontrem, digamos, uma maneira de estarem presentes às palestras do etnógrafo. Ganha-se muitas coisas (ao menos potencialmente), é claro, desse acesso emergente aos bastidores, e 
o fato de estes sujeitos de pesquisas estarem minando este novo portal é apenas um dos aspectos da mudança de estado das relações etnográficas. Faz sentido pensar seriamente sobre como os etnógrafos estão se redisciplinando num mundo em que os bastidores (em "casa") continuam a se retirar da visão etnográfica. Pode ser outro nivelamento do campo de jogo etnográfico, talvez até um que seja bem-vindo, mas ele demanda a reconfiguração do contexto etnográfico para que inclua o tipo de ciclos de feedback e de trocas pós-trabalho-de-campo que a internet e outros aparelhos tecnológicos (cada vez menos caros) proporcionam.

Johannes Fabian (2008) escreveu sobre a possibilidade de um "arquivo virtual" que permita aos etnógrafos disseminar material de forma rápida, fornecendo oportunidade para respostas quase imediatas e para críticas dos próprios sujeitos das pesquisas. Esse intercâmbio em tempo real não é apenas mais uma forma de pensar sobre a escrita etnográfica (outra desculpa para narrativas "dialógicas". Ele pode marcar também o início de um conjunto de relações totalmente diferentes entre os etnógrafos e seus pretensos sujeitos. Não importa onde estejam (e, cada vez mais, não importa o grau de instrução formal que tenham alcançado), a internet está se tornando um útil mecanismo para vexar as aspirações do etnógrafo por uma espécie de voyeurismo unilateral. O investigador está cada vez mais investigável. E se uma parte fundamental do que se passa nos bastidores já não fica mais fora de visão, pelo menos não do jeito que ficava antes, poderíamos muito bem estar testemunhando uma mudança fundamental na natureza da pesquisa etnográfica e nas formas em que os etnógrafos podem ser responsabilizados por suas representações dos outros. Tal mudança, mesmo que mais sutil do que eu afirmo, deve ter sérias implicações para a forma como iremos realizar a escrita da cultura hoje.

Apesar de eu usar o termo sinceridade etnográfica para marcar algumas das tensões ultramodernas entre as regiões etnográfica e acadêmica, entre o palco central e suas vigas, não quero dizer de forma simplista que tal sinceridade é transportável sem maiores problemas, que é uma categoria universal aplicável sempre e em todos os lugares. Os antropólogos já forneceram exemplos convincentes de grupos sociais 
ao redor do mundo que não compartilham de formas "Ocidentais" básicas de entender subjetividade e individualidade [selfhood]. A linguista Bambi Schieffelin, por exemplo, trabalhou com uma comunidade na Papua Nova Guiné que tem pouca noção de interioridade subjetiva ou (in) sinceridade individual potencial, e nenhuma linguagem para imaginar um lado reverso no que as pessoas falam para além de seu valor nominal - isto é, antes do contato relativamente recente mantido com forasteiros ${ }^{4}$. Para os AHIJ, minhas próprias intenções e motivações para me engajar em sua comunidade são quase, em certo nível, além do mais, um mandato profético e uma intervenção divina que atuam como enquadres explicativos mais potentes do que qualquer conto que eu possa oferecer sobre como eu acabei tentando conduzir pesquisa com ou sobre eles. A diferença entre "com" e "sobre" tem implicações importantes para esta discussão, mas a minha sinceridade é o que está parcialmente em jogo no acerto de contas.

Muitos dos pesquisadores que estudam questões de identidade nos Estados Unidos demonstram que a autorrepresentação ou a falsificação não são as únicas formas de compreender selves ocidentais ou noções de individualidade [subjecthood]. Tudo isso é verdade, mas o meu objetivo é simplesmente sustentar a ideia de que a "sinceridade etnográfica" aponta para uma noção ligeiramente diferente de real - irreal numa paisagem global midiatizada - e para um campo etnográfico que está sendo concomitantemente reconfigurado em função de tecnologias de mídia ultramodernas e da digitalização da pesquisa etnográfica.

Refletindo sobre minha palestra na Califórnia, na volta para a Filadélfia, eu me arrepiei com algumas de minhas respostas excessivamente irreverentes para questões da audiência, com algum tom ocasional ou com escolhas terminológicas que pretendiam uma distanciação de minha "apresentação do eu" na kfar. Eu não posso ser hipócrita, ao menos espero que não, mas essa é uma questão empírica, uma questão que os santos AHIJ vão decidir. E eles têm cada vez mais acesso aos dados que precisam para decidir.

O digital reestrutura a possibilidade antropológica, criando novos enquadres e fotos das, a partir das e para as mais românticas paisagens 
oníricas disciplinares. As flexões no tempo e no espaço, operadas pela digitalidade, recalibram a relação diádica que serve de centro e de ponto de articulação para todo o encontro etnográfico. O projeto etnográfico tradicional, inquestionavelmente monológico na forma do legado malinowskiano, tornou-se digital, devemos continuar a pensar muito claramente sobre o que isso implica para o futuro da pesquisa antropológica e para as versões da "cultura escrita" que ela pode exigir, assim como levamos a sério a afirmação de que uma evocação acrítica do digital trafega em direção a um etnocentrismo muito confortável. O digital ainda pode ser bom para pensar. Se não servir para mais nada, ele exige o reconhecimento de que os "sujeitos" etnográficos já estão (e de forma bastante autoritária!) escrevendo, filmando e observando a si mesmos (e a nós) - e que isso pode ser (de forma bastante irônica) a salvação da disciplina daquilo que outros profetizaram como sua irrelevância pendente (Greenhouse, 2011) . Para roubar uma página de Riggs e Myerhoff, capturar ativamente nossa própria morte (em imagens, sons e palavras) pode ser uma forma de negociar esta morte disciplinar, este processo moribundo da disciplina, apenas mais uma forma de argumentar o que o futuro da etnografia é e não é.

\section{Notas}

1 Eu gostaria de agradecer à professora Deborah A. Thomas pela gentileza de ter revisado os primeiros esboços desta tradução. Seus comentários foram de grande valor paraque eu pudesse dar conta de questões teóricas e estilísticas.

2 Em 2011, o Príncipe Nasi Asiel fez uma ruptura bastante pública com Ben Ammi e os African Hebrew Israelite of Jerusalem depois de mais de 40 anos de serviço à comunidade. Embora eu não vá discutir isso aqui, acredito que essa separação recente é uma coisa importante a ser analisada se se quer compreender a fluidez das espiritualidades Afro no século XXI. Deixo essa discussão para um momento posterior.

3 A comunidade também é impassivelmente contra a homossexualidade, que, juntamente com a dieta onívora de Riggs (como sinalizado pela literalização de seu filme de uma metáfora gumbo), seria parte do que eles usariam para explicar sua mortalidade física. Estas são manifestações, argumentariam eles, de um desrespeito pela aliança dos nossos antepassados com Yah, um desrespeito que se traduz diretamente na inevitabilidade da morte. A vida eterna, argumentam eles, só é possível por meio da reparação das ligações com Yah (isto é, obedecendo a seus mandamentos).

4 Bambi Schieffelin transmitiu esta questão para mim em uma conversa que tivemos depois de uma apresentação do meu trabalho anterior sobre raça e sinceridade. Algumas de suas pesquisas sobre ideologias linguísticas entre as comunidades 
do Pacífico (por exemplo, Makihara e Schieffelin (2007)) ajudam a analisar tais pressupostos culturalmente específicos. Da mesma forma, de acordo com Webb Keane (2002), superinvestimentos em tamanha sinceridade são, muitas vezes, uma espécie de predileção ou empréstimo cristãos (especificamente protestante). Para a minha própria visão sobre a sinceridade, autenticidade e raciocínio racial, ver Jackson (2005).

5 Greenhouse (2011) problematiza bastante essa noção de relevância sociopolítica vis-à-vis a prática e a escrita etnográficas.

\section{Referências}

BARTHES, Roland . Camera Lucida. New York: Farrar, Straus and Giroux, 1981.

CLIFFORD, James; MARCUS, George E. (Org.). Writing Culture: the Poetics and Politics of Ethnography. Berkeley: University of California Press, 1986.

COMAROFF, Jean; COMAROFF, John L. Ethnicity, Inc. Chicago: University of Chicago Press, 2009.

CSORDAS, Thomas. Body/Meaning/Healing. New York: Palgrave, 2002.

EVERETT, Anna. Digital Diasporas: a Race for Cyberspace. Buffalo: State University of New York, 2009.

FABIAN, Johannes. Ethnography as Commentary: Writing from the Virtual Archive. Durham, NC: Duke University Press, 2008.

GEERTZ, Clifford. The Interpretation of Cultures. New York: Basic Books, 1973.

GINSBURG, Faye. Rethinking the Digital Age. In: HESMONDHALG, David; TOYNBEE, Jason (Org.). The Media and Social Theory. New York: Routledge, 2008. p. 127-144.

GREENHOUSE, Carol. The Paradox of Relevance: Ethnography and Citizenship in the United States. Philadelphia: University of Pennsylvania Press, 2011.

GRIMSHAW, Anna. The Bellwether Ewe: Recent Developments in Ethnographic Filmmaking and the Aesthetics of Anthropological Inquiry.

Cultural Anthropology, [S.l.], v. 26, n. 2, p. 263-286, 2011.

HARRISON, Faye. Decolonizing Anthropology: Moving Further toward an Anthropology of Liberation. Washington, DC: American Anthropological Association, 1997. 
JACKSON JR., John L. Real Black: Adventures in Racial Sincerity. Chicago: University of Chicago Press, 2005.

KEANE, Webb . Sincerity, "Modernity," and the Protestants. Cultural Anthropology, [S.l.], v. 17, p. 65-92, 2002.

KEELING, Kara. Passing for Human: Bamboozled and Digital Humanism. Women and Performance, [S.l.], v. 15, n. 1, p. 237-250, 2005.

MAKIHARA, Miki; SCHIEFFELIN, Bambi B. Consequences of Contact: language ideologies and sociocultural transformations in pacific societies. Oxford: Oxford University Press, 2007.

MYERHOFF, Barbara. In Her Own Time: the Final Fieldwork of Barbara Myerhoff. Santa Monica: Direct Cinema, 1985.

PETERS, John Durham. Speaking into the Air: a History of the Idea of Communication. Chicago: University of Chicago Press, 1999.

RIGGS, Marlon. Tongues Untied: Black Men Loving Black Men. San Francisco: Frameline, 1989.

Black Is, Black Ain't. San Francisco: California Newsreel, 1994.

URBAN, Greg. Metaculture: How Culture Moves through the World. Minneapolis: University of Minnesota Press, 2001.

WALLACE, Anthony. Revitalization Movements. American

Anthropologist, [S.l.], v. 58, n. 2, p. 264-281, 1956.

Recebido em 05/09/2016

Aceito em 24/06/2017 